Bernd Schneidmüller: Europäische Erinnerungsorte im Mittelalter, in: Jahrbuch für Europäische Geschichte 3, 2002, S. 39-58.

Die Seitenzahlen des Word-Dokuments entsprechen nicht den Seitenzahlen der Druckfassung

\title{
Europäische Erinnerungsorte im Mittelalter ${ }^{1}$
}

von Bernd Schneidmüller

Das Konzept der Erforschung von Erinnerungsorten im weiteren Sinn, jenen „lieux de mémoire“, wie sie die französische Forschung definiert hat, bezieht seinen Reiz aus der Verknüpfung unterschiedlicher Bezugsfelder ${ }^{2}$. Im Hintergrund steht sogar ein totales System, das Erinnerung und Gedächtnis, Vergangenheit wie deren Aktualisierung als anthropologische Grundgegebenheit begreift. Alle Kultur ist Erinnerungskultur, ob sie historisch ausgestaltet wird oder sich gegen die Geschichte definiert. Die deutsche Forschung hat dieses Phänomen neuerdings aus der Totalität von Memoria und aus der gegenwartsbezogenen Kraft der Gedächtniskultur beschrieben ${ }^{3}$.

Erinnerung macht sich nicht allein an historischen Plätzen, Stein gewordenen Monumenten der Vergangenheit, Herrschaftszeichen oder zu Symbolen erwachsenen Gegenständen fest. Auch Ideen, Institutionen, Imaginationen oder Konstrukte können zum produktiven Ausgangs- wie Anknüpfungspunkt eines Interesse-geleiteten Gedenkens werden. Es entfaltete besondere Wirkkraft, wenn sich Institutionen und abstrakte Wertvorstellungen mit konkreten Orten, Gegenständen oder Symbolen verknüpfen ließen. Die meisten Beispiele sind nicht umsonst aus der französischen Geschichte entwickelt worden: die Erfahrbarkeit der Institution Monarchie in der Königsgrablege von St-Denis oder in der Weihehandlung von Reims, die Projektion der Nation auf den Monarchen oder auf monarchisch-ständische Ritualhandlungen, die Verknüpfung des historischen Bewußtseins vom Vorrang bei Gott und den Menschen mit den Heiligen und ihrer Präsenz in den Grabeskirchen von St-Denis, St-Remi in Reims oder St-Martin in Tours, die Materialisierung kollektiven Bewußtseins in Symbolhandlungen wie der Verehrung des Himmelsöls in der „sainte-ampoulle“ von Reims oder wie der Einholung der Oriflamme von St-Denis ${ }^{4}$.

Das von Pierre Nora aus der französischen Geschichte entwickelte Modell der „lieux de mémoire“ wirkt deshalb mit hoher Suggestionskraft, weil sich Historikerinnen und Historiker vielerorts an den Diskussionen um Denkmäler, um das Sichtbarmachen von Institutionen oder erfahrbarer Vergangenheit für die Gegenwart beteiligen. Wieviel Mythos braucht die Moderne noch, wieviel Erinnerung unsere Gegenwart? Welchen 
Anteil besitzen die Geschichte und ihre Hüter am Funktionieren unserer Gemeinwesen und am supranationalen Experiment der Europäischen Gemeinschaft? Wer die Bedeutung von Erinnerungsorten in der Geschichte studiert hat, der läßt sich mit guten Gründen von dem Gedanken erfüllen, daß alle Großgruppen-, Staaten- und Gemeinschaftsbildungen ihre „lieux de mémoire“ benötigen. Ob Historikerinnen und Historiker solche Kreationen nur beobachten oder sich an deren Schaffung und Pflege beteiligen sollen, hängt gewiß vom gewollten Ort der Geschichtswissenschaft in der Gesellschaft oder vom Bewußtwerden der Kulturwissenschaften um ihre materiellen Abhängigkeiten wie um ihre intendierte sinnstiftende Rolle ab.

Wenn in dieser Sammlung auch die Mediaevistik zu Wort kommt, dann sollte sie zunächst den Zauber der Konfiguration „Erinnerungsorte“ relativieren, bevor sie ihre Befunde ausbreitet. Die internationale Forschung zehrt von französischen Methoden und Ergebnissen, welche die Richtung des Blicks einstellen. In einem langen, komplizierten und keineswegs geradlinigen Prozeß entstand seit dem 9. Jahrhundert die französische Königsnation, die „lieux de mémoire“ aus ganz unterschiedlichen Wurzeln und Regionen zu einem scheinbar homogenen Ganzen zusammenfügte: Monarchie, Adel, Nation, St-Denis, St-Martin und St-Remi, den Zauber von Weihe und Salbung, das Wissen um den besonderen Ort bei Gott und den Menschen, die kulturelle, sprachliche, literarische, künstlerische Überlegenheit und Vorbildfunktion für Europa, in den nachmittelalterlichen Jahrhunderten dann die Gewißheit der Vorreiterrolle in der historischen Freiheitsdynamik und in der Schaffung der modernen Nation aus der Französischen Revolution. Eine solche historische Konsistenz läßt sich in anderen Teilen Europas nur schwer finden, weil dort personalisierte Institutionen ungleich weniger integrationsmächtig waren. Damit tritt eine Verknüpfung von Institution, Trägergruppe, Rezeption, Propaganda und pflegender Entfaltung in der Blick, die für die abendländische Erinnerungsgeschichte von entscheidender Bedeutung wurde.

Gewiß sind in vielen Teilen des mittelalterlichen Europa vergleichbare Entwicklungen wie in Frankreich zu beobachten, doch das viel strapazierte Modell bezieht seinen Glanz gerade aus der Einzigartigkeit ${ }^{5}$. Auch andernorts stilisierte man Heilige durchaus zu Integrationsfiguren von Gruppen, Städten, Verbänden oder Völkern. Der heilige Dionysius stand neben manchen anderen, dem heiligen Olaf, dem heiligen Wenzel, dem heiligen Heinrich und den vielen Stadtheiligen ${ }^{6}$. Der Kult um Gräber oder Reliquien diente als Anknüpfungspunkt von Erinnerung für die Gegenwart. Auch im Wissen um das Alter des eigenen Volkes besaßen die Franzosen mit ihrer Idee der trojanischen Herkunft selbstbewußte Partner in Europa ${ }^{7}$. Die Sachsen führten sich auf das Heer Alexanders des Großen, die Bayern auf armenische Vorfahren zurück. Doch mit der räumlichen Konzentration des französischen Königtums und seiner Sakralisierung konnten sich nur wenige Monarchien messen. Selbst die ostfränkisch-deutschen Könige, 
die seit 962 aus der Hand des Papstes die Kaiserkrone empfingen und damit in eine von Karl dem Großen begründete und auf antiken Vorbildern ruhende einzigartige Tradition hineinwuchsen, ließen sich bei allem Selbstbewußtsein im Spätmittelalter vom Glanz der allerchristlichsten Könige beeindrucken. Das beruhte gewiß weniger auf dem Rang vornehmer Reliquien, sondern eher auf einem Modernisierungsvorsprung auf Grund des ökonomischen, administrativen, demographischen, sozialen und kulturellen Gefälles in Europa von West nach Ost ${ }^{8}$. Die Entfaltung der materiellen und immateriellen Erinnerungsorte wurde wesentlich von politischen und wirtschaftlichen Rahmenbedingungen gesteuert. Also gewannen die westeuropäischen Höfe ihren Modellcharakter für die ritterliche Kultur des späten Mittelalters und der frühen Neuzeit ${ }^{9}$.

Wer das von Pierre Nora entwickelte Modell auf das Alte Reich übertragen wollte, geriete wegen der offensichtlichen Unterschiede rasch in Bedrängnis: Ein dominierendes Reichsvolk, das seine Geschichte, Sprache ${ }^{10}$ und Literatur mit normativer, höfischer Strahlkraft im Reich ausbreitete, gab es ebensowenig wie einen besonderen, verbindlichen Reichsheiligen ${ }^{11}$. Selbst der wichtige Erinnerungsort Aachen, wo mit Karl dem Großen der Begründer des Westkaisertums ruhte und seit 1165 auf Betreiben Friedrich Barbarossas der Heiligenkult gepflegt wurde, selbst Aachen vermochte auf Grund seiner Randlage im Reich nicht jene integrative Kraft wie das Ensemble von St-Denis und Paris - mitten in Frankreich - zu entfalten. Der Wahl- und Erinnerungsort Frankfurt am Main verknüpfte sich zwar mit Kurfürstenkolleg und Königswahl, später auch mit der Kaiserkrönung. Doch eine institutionelle Instrumentalisierung in weitgehender spätmittelalterlicher Königsferne gelang hier ebensowenig wie im noch ferneren Rom. Die von Luxemburgern, Wittelsbachern oder Habsburgern geförderten Erinnerungsorte oder Grablegen in Prag, München oder Wien gewannen ihre Wichtigkeit zuvorderst für die Dynastien und ihre Territorien. Für das Reich erlangten sie allenfalls als Aufenthaltsorte der Herrscher und damit als Zielpunkte beschwerlicher Reisen Bedeutung. Weil im Reich der Aktionsraum der Könige nur bedingt mit den Erinnerungsorten des Reichs zusammenfiel, entfaltete sich selbst der Kult der heiliggesprochenen Kaiser und Amtsvorgänger vor allem als Angelegenheit des Klerus ihrer Grabeskirchen. So fand die Heiligenverehrung Heinrichs II. zuvorderst in Bamberg, die Karls des Großen zuvorderst in Aachen statt und wurde nur zeitweilig für die Idee einer transpersonalen Monarchie instrumentalisiert ${ }^{12}$.

Es wäre durchaus interessant, im Gefolge von František Graus und seinem in der deutschen Forschung ziemlich vereinzelt stehenden Buch über „Lebendige Vergangenheit“"13 Leitfiguren des Verhaltens, Herkunfts- und Abstammungssagen, heilige Repräsentanten, mittelalterliche Vergangenheitsbilder oder Helden und ihre lokale „Materialisierung“ vergleichend $\mathrm{zu}$ studieren ${ }^{14}$. Doch hier gilt es nach 
europäischen, nicht nach nationalen, regionalen, lokalen oder gruppenbezogenen Erinnerungsorten zu fahnden. Gleichwohl waren diese einleitenden Gedanken unerläßlich, um für das offene Forschungsprojekt „lieux de mémoire“ zunächst Abhängigkeiten der Erkenntnis von Interesse und nationalen Wissenschaftstraditionen zu ermitteln und als Korrektiv für rasche übernationale Erwartungen herauszustellen. Sodann bleibt die Kenntnis personaler wie institutioneller Bindungen bei Entstehung, Wandel und Pflege von Erinnerungsorten unerläßliche Voraussetzung allen weiteren Nachdenkens.

Darum müßte man redlicherweise die Einladung zu einem weitgefaßten Beitrag über europäische Erinnerungsorte im Mittelalter angesichts der Überlieferung, des Forschungsstandes und der Probleme bei der Instrumentalisierung von Geschichte ablehnen. Denn wer sollte in einem Europa, das sich im Mittelalter nur schwerlich als politische Einheit verstand ${ }^{15}$, Erinnerungsorte europäischer Prägung und Strahlkraft hervorbringen und entfalten? An welcher Person oder welcher Institution hätte sich die Idee Europa im Mittelalter überhaupt kristallisieren können? Sowohl das Papsttum als auch das Kaisertum verstanden sich wenigstens in der Theorie als universale Mächte. Rom wurde als caput mundi, nicht als Haupt Europas bezeichnet. Panegyriker der Karolingerzeit hatten den ersten Westkaiser, den Frankenherrscher Karl den Großen, zwar als pater Europae, als Vater Europas, schließlich als Gipfel oder Leuchtturm Europas gepriesen. Doch das erfolgte an der Wende vom 8. zum 9. Jahrhundert aus den Debatten um die angemessenen Bezugspunkte seines Kaisertums, um Rombindung und fränkische Traditionswahrung ${ }^{16}$. So wie Karl Martell mit den christlichen Europenses bei Tours und Poitiers die Araber bezwungen hatte ${ }^{17}$, so konnten sich insulare und fränkische Dichter in einem europäischen Kaisertum des großen Karolingers verbunden sehen. Als Karls Erben den römischen Kaisertitel aufnahmen, war die rasche Konjunktur Europas fast schon beendet. Zu verlockend gestaltete sich die strahlende Wirkung des antiken Römerreichs, zu lebendig die Anziehungskraft der römischen Apostelgräber auf die Franken, als daß sich die bloße Beschränkung auf Europa als den dritten Teil der Welt (tertia pars mundi) hätte als Alternative durchsetzen können. Zwar zögerte Otto der Große bei der Wiedererrichtung eines machtvollen Westkaisertums mit dem Rombezug, doch auch hier erlagen der Sohn und seine Erben in Konkurrenz zu Byzanz dem römischen Kaisernamen und damit der Geltung einer Stadt, die durch die Jahrhunderte als Haupt des Erdkreises gefeiert wurde ${ }^{18}$. Als Zierde Europas, als decus Europae, benannte ein apulischer Fürst noch im frühen 11. Jahrhundert Kaiser Heinrich II. ${ }^{19}$. Doch die politische Instrumentalisierung des Europagedankens vollzog sich erst unter dem Eindruck der Türkengefahr im 15. Jahrhundert ${ }^{20}$. Wer durfte für den bedrohten Kontinent denken, sprechen oder handeln, der Papst, der Kaiser, ein Konzil der Kirche oder ein Bund der Fürsten? Den verwirrenden Konzepten des ausgehenden 
Mittelalters entsprach die Vagheit der Kristallisationspunkte und der geringe Grad der Institutionalisierung in der politischen Willensbildung.

Längst hatten Kaiser oder Papst ihre Integrationsfähigkeit eingebüßt. Die Christenheit mochte zwar faktisch auf Europa beschränkt sein, verstand sich in ihrem Missionsauftrag wie in ihren Bezugspunkten aber stets als universale Religion ${ }^{21}$. Die lateinische Kultur mit der Vatersprache Europas, ihr Bildungsmonopol an den europäischen Universitäten noch zäh verteidigend, wurde damals zunehmend durch nationale oder regionale Literatur- und Kommunikationssysteme abgelöst. Die Raumerfahrungen griffen längst über den dritten Teil der Welt hinaus, nach Osten, nach Süden und schließlich nach Westen. Die Kenntnis der antiken Mythologie und der Geschichte von der geraubten Königstochter ${ }^{22}$ ist durch die Jahrhunderte zwar nachzuweisen, formte aber keine gemeinschaftsstiftende Herkunftsgeschichte über den vielfältigen Abstammungssagen der europäischen Völker aus.

Darum führt die bloße Bezugnahme von Erinnerungsorten auf den Europabegriff ins Leere. Eine Gedächtniskultur, die sich an Wort oder Idee Europa festmachte, existierte allenfalls temporär, situations- und ortsbezogen, nie durchgehend oder mit integrativer Kraft. Alle Beschwörungen europäischer Kontinuitäten seit unvordenklichen Zeiten erweisen sich darum als Konstrukte, die Geschichte flott für eine aufnahmebereite Gegenwart instrumentalisieren. Diese Hinweise auf die Vielfalt täuschen freilich nicht darüber hinweg, daß das europäische Mittelalter aus gemeinschaftlichen Elementen lebte, die Gruppen und Völker, Regionen, Länder und Nationen verbanden und überwölbten. Von entscheidender Bedeutung für die historische Arbeit an den daraus erwachsenden „lieux de mémoire“ sind weniger unsere Kenntnisse eines gemeinschaftsstiftenden kulturellen Gedächtnisses, sondern mittelalterliche Wahrnehmungen gemeinsamer Voraussetzungen, Verlaufsformen und Anknüpfungspunkte. Sie stifteten nicht etwa europäische Identitäten, sie wurden noch nicht einmal als spezifisch europäisch bewußt. Aber sie gehörten zur Identität der in Europa lebenden Menschen hinzu.

Für den Diskurs mit Historikern, die sich mit der Antike oder der Neuzeit beschäftigen, muß der Mediaevist darum mit einem weiten qualitativen Raster von „Erinnerungsorten“ arbeiten. Dieses Vorgehen besitzt zwar den Nachteil des Unspezifischen, führt aber gerade deshalb in den Kern der Diskussion über die epochenübergeifende Tauglichkeit des Forschungskonzepts „lieux de mémoire“. Aus europäischen Perspektiven sollen fünf zentrale Bezugsfelder einer gemeinschaftsstiftenden Gedächtniskultur knapp angesprochen werden. 
Die Gliederung der Welt in die drei Erdteile Asien, Europa und Afrika machte die entscheidende Grundlage mittelalterlicher Wahrnehmungskonzepte aus. Auf den Weltkarten in T-Form ${ }^{23}$ nahm Asien die Hälfte des Erdkreises ein, Europa und Afrika jeweils ein Viertel. Jerusalem bildete den Mittelpunkt der Welt. Diese Deutung aus dem Ganzen wurde entscheidend für das geographische wie heilsgeschichtliche Bewußtsein des Mittelalters und verhinderte lange eine auf Europa beschränkte Kartographie. Erst seit dem 12. Jahrhundert, beginnend mit dem Liber Floridus des Lambert von St-Omer, ordnete man der eigenen Lebenswelt ein größeres Darstellungsinteresse zu. Honorius Augustodunensis unterschied Europa bereits in unserem modernen Sinn von Ost nach West nach Scithia, Germania Superior und Germania Inferior (mit Dania und Norweia), Grecia, Italia, Gallia, Hispania und Britannia ${ }^{24}$.

Isidor von Sevilla hatte dem Mittelalter das biblische Wissen von der Aufteilung der Welt unter Sem, Japhet und Cham, den drei Söhnen Noahs, überliefert und präzisiert. In Abwandlung der Völkertafel des Alten Testaments (Gen 10) billigte Isidor Japhet und seinen Nachkommen das Land vom Taurus nach Westen zu, nämlich die Hälfte Asiens und ganz Europa bis zum britischen Meer $^{25}$. Auch diese Lehre fügte in biblischer Tradition die europäischen Völker mit den Brudervölkern der übrigen Welt zusammen, vom gleichen Urahn Noah abstammend. So entstand allmählich die Deckungsgleichheit von drei Kontinenten mit drei Völkergruppen ${ }^{26}$. In seiner Imago mundi legte Honorius Augustodunensis eine entscheidende Fährte, wenn er das im Mittelalter weiterentwickelte geographische Wissen der Bibel sozialgeschichtlich auflud und aus seiner Lektüre der Genesis verkündete: Schon in biblischer Zeit wurde das Menschengeschlecht in drei Stände aufgeteilt, in Freie, Krieger und Sklaven. Die Freien stammten von Sem, die Krieger von Japhet und die Sklaven von Cham ab. Im Gegensatz zu den Kindern Chams (Gen 9) besaßen Japhets Nachkommen Anteil am Heil $^{27}$. Isidor zählte mit der heiligen Schrift (Gen 10, 2-4) noch 15, Gottfried von Viterbo verzeichnete dann schon 23 Völker in der Nachfolge Japhets ${ }^{28}$.

Es ist kennzeichnend, daß seit dem 12. Jahrhundert auch die Geschichte der Europa als Tochter Agenors in die enzyklopädischen Zusammenstellungen eines Wissens verwoben wurde, dessen Zweck Sammlung wie Ordnung von Geographie, Geschichte und Heilsgeschichte war. In einem solchen Modell konnte - der Landnahme von Japhets Erben folgend - die christliche Botschaft von ihrem Ursprung im Osten zu ihrer Erfüllung im Westen wandern. Europa wurde zum Ziel- und Höhepunkt des Heils, blieb aber geographisch wie ethnisch stets in den Kosmos von Erdteilen und Völkern eingebunden.

\section{2) Ausgang und Ziel des Heils}


Der wichtigste europäische Erinnerungsort des Mittelalters lag in Asien. In Jerusalem hatte der Bund Gottes mit den Menschen seinen sichtbaren Niederschlag erfahren. Diese Stadt wurde zum Modell für die heiligen Städte des Mittelalters. Ihre Erfahrungen schöpften die vielen Imitatoren aus der Bibel. Die Schriften des Alten Testaments stilisieren Jerusalem zum Ort der Gegenwart Gottes, zur Stadt der Dynastie Davids (2 Sam 6), des Herrn (Is 60, 14), der Gerechtigkeit, nach der Erneuerung schließlich zum Thron des Herrn (Jr 3, 17) und zum Herrschaftssitz des messianischen Davidsohns (Is 9, 6). Weil Gott hier „mitten unter den Israeliten“ leben will (Ex 29, 43-46; Sach 8, 3), wird Jerusalem zum Zielort der großen Pilgerschaft aller Völker (Is 2, 2-5; 60-62). Die spätjüdische Tradition versetzt Jerusalem dann ins Transzendente, macht es zum Ort des Lebensbaums wie des Paradieses; ein jenseitiges, ewiges Jerusalem bildet den Aufenthaltsort der Gerechten. Das Neue Testament kündet zwar davon, daß Jerusalem seinen Heiland verschmähte, doch die Stadt birgt weiter alle Heilshoffnung in sich. Der Hebräerbrief erhebt Jerusalem in eine obere oder zukünftige Sphäre und läßt Christus als den wahren Hohepriester zum Wegbereiter ins zukünftige Allerheiligste erwachsen (Hebr 13, 14). In der Offenbarung des Johannes wird Jerusalem schließlich zur Braut des Lammes und zum Gegenbild der Hure Babylon (Apoc 21, 2 - 22, 5). Die mit Gold und Edelsteinen geschmückte Stadt dient als Sinnbild der zwölf Stämme Israels wie der zwölf Apostel Christi und wird zum Paradies mit dem Baum des Lebens ${ }^{29}$.

Immer wieder schufen sich Theologie, Philosophie, Literatur und Kunst ihre Abbilder dieses himmlischen Jerusalems. Buch- wie Wandmalerei und die mittelalterliche Sakralkunst bezeugen die mittelalterlichen Vorstellungen von den Paradiesflüssen oder vom Lebensbaum, in der Bamberger Apokalypse, im Vierungsgewölbe des Braunschweiger Doms, auf dem Wirkteppich von Angers oder im Flügelrentabel des Genter Altars Jan van Eycks. Die berühmten Radleuchter aus dem Hildesheimer Dom oder der Aachener Marienkirche setzen das Bild der türmebewehrten Stadt in Szene und vervielfältigen für die schauenden Gläubigen das himmlische Jerusalem als zentralen Erinnerungsort der mittelalterlichen Christenheit.

Die Kirchenväter lehrten zwar die Unterschiede zwischen dem realen und dem himmlischen Jerusalem. Doch schon Hieronymus ließ sich vom Zauber Palästinas gefangennehmen, als er sich in Bethlehem ansiedelte. Der zunehmenden Präsenz des Erinnerungsorts auf Pergamentseiten und Kunstwerken entsprach das Wegrücken Jerusalems aus der realen Erfahrung. 614 wurde die Stadt erstmals von den Sassaniden erobert, 638 gelangte sie endgültig in den Herrschaftsbereich des Islam. Im 7. Jahrhundert entstand hier der Felsendom, Zeugnis für Jerusalems Rang als dritter heiliger Stadt des Islam, bald darauf die Al-Aqsa-Moschee. Wenige Pilger des lateinischen Westens kündeten im Frühmittelalter von ihren Jerusalemerfahrungen ${ }^{30}$. Vereinzelte Pilgerreisen erwuchsen im 11. Jahrhundert zu einem kollektiven Phänomen, 
das seinen Höhepunkt in wiederholten Kreuzzügen der abendländischen Christenheit nach Palästina erreichte ${ }^{31}$.

1099 wurde Jerusalem von den Kreuzfahrern erobert, die bald darauf ein lateinisches Königreich um die Grabeskirche des Herrn errichteten und Nichtchristen aus der Stadt wiesen $^{32}$. Alte und diffuse Sehnsüchte fanden damals ihre Erfüllung, ohne daß reale Dauerhaftigkeiten europäischer Existenz im wichtigsten Erinnerungsort der Christenheit wirklich zu garantieren gewesen wären. Immerhin gehörte im 12. und 13. Jahrhundert die Wallfahrt ins Heilige Land zum Standardprogramm der christlichen Ritterschaft und ergriff auf bisweilen tragische Weise nahezu alle Gruppen der Bevölkerung, Arme und Kinder, Städter und Bauern, Kleriker und Mönche, Adlige, Könige und Kaiser.

Der Zauber der heiligen Stadt überdauerte auch die Eroberung Jerusalems durch Sultan Saladin im Jahr 1187 und erlebte im 14. und 15. Jahrhundert einen gewaltigen Aufschwung. In nahezu tausend Jahren, zwischen 333 und 1291, waren ungefähr 200 Pilgerführer entstanden, allein im 15. Jahrhundert kamen etwa 400 neue hinzu. Nur für wenige Jahrzehnte beherrschten Christen im Hochmittelalter den Schauplatz von Leiden und Sterben Jesu, den Ort ihrer Hoffnung im Jüngsten Gericht. 1229 inszenierte Kaiser Friedrich II. seine Krönung - konzeptionell vielfältig umstritten - in der Grabeskirche des Herrn zur Demonstration seiner imperialen Macht in der Heiligen Stadt ${ }^{33}$. Doch seit 1244 blieb der über die Jahrhunderte weitergeführte Titel eines Königs von Jerusalem (rex Iherusalem) nur noch inhaltsleerer Anspruch.

Die Gelehrten kannten freilich die Prophezeiungen vom Antichristen, die im 10. Jahrhundert Adso von Montier-en-Der in seiner fiktiven Biographie („Vom Erscheinen und von der Zeit des Antichristen“ - De ortu et tempore Antichristi) aus älteren Quellen erstmals zusammenstellte: Als Jude vom Stamme Dan in Babylon geboren und von Magiern erzogen, werde der Antichrist nach Jerusalem ziehen und von dort aus mit der Behauptung, Gottes Sohn zu sein, seine Herrschaft über die ganze Welt etablieren. Endlich werde ihn Gott auf dem Ölberg durch den Hauch seines Mundes und durch den Erzengel Michael töten ${ }^{34}$. Mit dem apokalyptischen Wissen vom Ende der Welt, von der Herrschaft des Antichristen und vom Jüngsten Gericht lebte das christliche Mittelalter. Man mag dieses Endzeitbewußtsein auch in die Reihe der „lieux de mémoire“ ordnen. Entscheidend wurde seine Verknüpfung mit Jerusalem als dem zentralen Erinnerungsort der christlichen Botschaft. Seit dem 4. Jahrhundert entstand die Lehre vom letzten römischen Kaiser vor dem Weltende, der alle Nichtchristen entweder bekehren oder vernichten, ein irdisches Friedensreich schaffen und endlich nach Jerusalem ziehen würde, um dort seine Herrschaftszeichen niederzulegen und seine Macht an Gott zurückzugeben. So wurde die Heilige Stadt zum Ausgangs- wie zum Zielpunkt der christlichen Heilsgeschichte ${ }^{35}$. 


\section{3) Fremde Ursprünge}

Durch die Übernahme der antiken Buchreligion fand das mittelalterliche Europa den Wurzelgrund seines Glaubens wie den Zielpunkt seiner Geschichte im fernen Palästina. Dem entsprach durchaus das Wissen um die Herkunft der eigenen Völker und Nationen aus weiträumigen Verlagerungen. Seit der Wende vom 5. zum 6. Jahrhundert entwickelte sich das Frankenreich von einer spätantiken Randkultur zum selbstbewußten Gestalter des europäischen Mittelalters ${ }^{36}$. Diese Großreichsbildung veränderte die politische Geographie und die Kultur der bekannten Welt, schloß das lange Ende der Antike endgültig ab und bahnte durch Schwerpunktverschiebungen nach Norden und Westen der Idee des Abendlands entscheidende Wege.

Zur Akkulturation der Franken in der okzidentalen Welt gehörte die Kreation einer angemessenen Abstammungslehre. Wie die Römer versicherten sich die Franken nämlich ihrer Herkunft aus Troja und rückten damit an Alter und Würde als Brudervolk neben die Römer. In seiner Frankenchronik berichtete der sogenannte Fredegar unter Hinweis auf scheinbare Quellen wie Hieronymus und Vergil die folgende Herkunftsgeschichte: „Ihr erster König sei Priamus gewesen; als Troja durch die List des Odysseus erobert wurde, seien sie von dort fortgezogen und hätten dann Friga als ihren König gehabt; sie hätten sich geteilt, und der eine Volksteil wäre nach Mazedonien gezogen, der andere hätte unter Friga - sie wurden als Frigier bezeichnet Asien durchzogen und sich am Ufer der Donau und am Ozean niedergelassen; dann hätten sie sich nochmals geteilt, und die Hälfte von ihnen sei mit ihrem König Francio nach Europa gezogen. Sie durchwanderten Europa und besetzten mit ihren Frauen und Kindern das Ufer des Rheins; nicht weit vom Rhein versuchten sie, eine Stadt zu erbauen, die sie nach Troja benannten. Dieses Werk wurde zwar begonnen, aber nicht vollendet. Der andere Teil, der am Ufer der Donau zurückgeblieben war, erwählte sich Torcoth zum König, nach dem sie in diesem Lande Türken genannt wurden; und die anderen wurden nach Francio als Franken bezeichnet“37.

Die fränkische Trojanersage erfuhr im Lauf des Mittelalters vielfältige Entfaltung und Aktualisierung, die immer wieder an die unmittelbare Gegenwart heranführte: Mit dem Urahnen Priamus verließen die trojanischen Vorfahren der Franken die zerstörte Stadt zu einer abenteuerlichen Reise durch die Asowschen Sümpfe und das Land an der Donau. In Thrakien, in der sagenhaften Stadt Sicambria, siedelten sie unter ihren Königen Francio und Turchus. Vom römischen Kaiser Valentinian wegen ihrer Freiheitsliebe vertrieben, eroberten sich die Franken ihre neue Heimat an den Ufern des Rheins, um von hier aus ein Großreich in Nordgallien zu bilden. Flexibel wurde dieses Grundgerüst der Sage fortentwickelt, in die man sogar einen Parisius 
hineinkomponieren konnte. Er wurde für einen raschen Trojanerzug nach Paris und für die dadurch herausgehobene historische Stellung der späteren französischen Hauptstadt verantwortlich gemacht ${ }^{38}$.

Mit beachtlicher Kreativität sicherten sich Dynastien wie die Kapetinger, die Welfen oder die Habsburger ihre trojanische Abstammung. Hinzu trat das bayerische Wissen vom armenischen, das sächsische vom makedonischen Ursprung ${ }^{39}$. Die Herkunft aus Asien garantierte im Völkerkontinuum der alten Welt allemal Vornehmheit und Gleichrangigkeit, vermittelte aber auch die Einsicht von raumgreifender Landnahme als Grundlage der mittelalterlichen Ordnung.

Schon im 6. Jahrhundert hatte Jordanes die permanente Wanderung und die wiederholte Landnahme als Prinzip der Volksgeschichte beschrieben. „Wie ein Bienenschwarm“ waren die Goten aus „dem Schoß der Insel“ Skandinavien nach Europa aufgebrochen (ab huius insulae gremio velut examen apium erumpens in terram Europae). Dort, im Norden, befinde sich die „Produktionsstätte der Völker und der Geburtsort der Nationen“ (officina gentium - vagina nationum) ${ }^{40}$. Das Wissen um die Volksentstehung in Wanderschaft und Landnahme bewahrten sich auch die anderen mittelalterlichen Völker, die auf dem Boden des Imperium Romanum ihre Reiche errichteten ${ }^{41}$. Noch im 12. Jahrhunderts brachte der unbekannte süddeutsche Verfasser der Historia Welforum die Lehre von der gewaltsamen Eroberung aufs Pergament, als er von der trojanischen Herkunft der Welfen und ihrer Herrschaftsbildung berichtete: „Wem das nicht glaubwürdig erscheint, der lese die Geschichten der heidnischen Völker. Da wird er finden, daß fast alle Länder gewaltsam von Fremden erobert und in Besitz genommen worden sind. Das pflegten die Trojaner zu tun, nachdem sie aus ihren Sitzen vertrieben worden waren, dies die Goten und die Alanen, dies die Hunnen und Wandalen, dies auch die Langobarden und die übrigen Volksstämme, besonders aber die nördlichen““42.

Hier bewahrte sich ein Autor des 12. Jahrhunderts das Wissen um die Wanderungsdynamik im Übergang von der Antike zum Mittelalter. Für Jordanes bildete Skandinavien die Geburtsstätte der Völker, für andere war es Asien. Das Wissen um diese Landnahme wie um die ungeheure Migrationsdynamik europäischer Völker wirkte auf die folgenden Jahrhunderte. Für solche „lieux de mémoire“ bildete das Bewußtsein fremder Ursprünge der eigenen Welt und ihres Glaubens geradezu den Wurzelgrund. Paßt dieser Befund noch zu unserem modernen Europa-Gedanken? Die Liebhaber einer Festung Europa möchten enttäuscht sein, denn die mittelalterlichen Länder und Kulturen Europas existierten gerade aus ihrer ungeheuren Sogkraft und der Aufnahmebereitschaft fremder Völker und Überzeugungen. Keine Ideen ethnischer Gleichförmigkeit, unveränderlicher Heimat oder beständiger Herrschaft drangen in die Köpfe. Europa lebte im Werden aus Umbruch, Zuwanderung und Eroberung, letztlich 
aus der „Europäisierung Europas“43. Die völlige Neuformierung des Kontinents, seiner in Wanderungen gewordenen Völker und seiner aus multipolaren Elementen erwachsenen Kultur wurde zum entscheidenden Fundament der mittelalterlichen Erinnerung. Erst als sich die aufgeklärte Neuzeit von den Mythen der alten Herkunftssagen löste, verwurzelte sie ihre Nationen in europäischer Erde und entwickelte den eigenen Kontinent zum Ausgangspunkt und Maß aller Zivilisation.

\section{4) Das römische Erbe}

Im scheinbaren Gegensatz zum Wissen um die ständige Wanderungsdynamik stand die auf antiken Vorbildern gründende Romidee, die sich an der unverrückbaren Stadt wie am Kaiser- oder Papsttum festmachte. Neben Jerusalem wurde Rom zum entscheidenden Erinnerungsort ${ }^{44}$ des mittelalterlichen Europa, der zudem den Vorzug größerer Zugänglichkeit und konkreter Erfahrbarkeit genoß. Mit vielen Epitheta wie urbs aeterna, urbs aurea, caput orbis oder domina mundi geschmückt, verbanden sich aus unterschiedlichen Interessenfeldern vielfältige Vorstellungen mit der Stadt, ihrer Geschichte und ihrer Sendung ${ }^{45}$. Im Anspruch prinzipiell auf die Welt ausgerichtet, reduzierten sich Rom und Romidee faktisch auf Europa.

Drei wesentliche Traditionsstränge dieser Romidee sind hervorzuheben ${ }^{46}$. Die kommunale Variante ging von der Vorstellung aus, daß die Bewohner Roms als Erben des antiken populus Romanus dessen Befugnisse in Gesetzgebung und Herrschaft übernommen hätten. Daraus wurde seit der Akklamation bei der Kaiserkrönung Karls des Großen das Anrecht auf die Vergabe des Kaisertums abgeleitet, mit dem Papst oder ohne den Papst. Da dieses Kaisertum seit der Erhebung Karls des Großen und Ottos des Großen faktisch auf das Abendland reduziert wurde, konkretisierte sich das universal formulierte Postulat tatsächlich auf das lateinische Europa.

Die kaiserliche Romidee griff zwar auf die universale Herrschaftsauffassung der antiken Imperatoren zurück, fügte aber die römische Kaiserkrönung seit 962 nahezu ausschließlich mit der Geschichte des ostfränkisch-deutschen Reiches zusammen, das sich nach Anspruch und Namen römisch darstellte. In der Wirklichkeit blieb Rom indes eine ferne Sonne, die dem Reich Licht und Leben einhauchte, ohne von ihm eigentlich erreicht zu werden. Die spätmittelalterliche Verfassungsrealität mit der Wahl des römischen Königs in Frankfurt am Main, seiner Krönung in Aachen und seinem anschließenden Romzug zur Kaiserkrönung unterstrich diese multipolare Prägung. Sie führte im Imperium mit seinen weiten Denk- und Handlungsspielräumen zum Verzicht auf eine nationale Konzentration nach dem Modell Frankreichs, Englands, Spaniens, Dänemarks, Ungarns oder Polens. Für Otto III. wurde die aurea Roma an der Jahrtausendwende zum wesentlichen Ausgangspunkt seiner Herrschaftsauffassung. Seit 
dem Kaisertum Konrads II. (1024-1039) trat dieser Rombezug in der Umschrift der Herrscherbullen hervor: Roma caput mundi regit orbis frena rotundi - „Rom, das Haupt der Welt, regiert den Erdkreis““77. Ein konkreter „Griff nach der Weltmacht“ läßt sich im Mittelalter indes nicht nachweisen, auch wenn einige Juristen oder Dichter manchmal ihre luftigen Gedankengebäude vom „Herrn der Welt“ (mundi dominus) oder vom gottgewollten „König über andere Könige“ auf das Pergament formulierten ${ }^{48}$.

Am geschichtsmächtigsten entwickelte sich die kirchliche Romidee, die sich mit dem Primatsanspruch des Papsttums aus der Nachfolge Petri verknüpfte. Die römischen Apostelgräber waren Zielpunkt kontinuierlicher Pilgerschaft aus allen Teilen der lateinischen Christenheit. In Europa konnte sonst nur noch ein weiteres illustres Apostelgrab verehrt werden, die vermeintliche Sepultur des ersten Apostelmärtyrers Jakobus in Santiago de Compostela ${ }^{49}$. Seit dem 12. Jahrhundert zog es eine zunehmende Pilgerschar an. Jerusalem, Rom und Santiago de Compostela wurden damit zu den wichtigsten Zielen des mittelalterlichen religiösen Unterwegsseins und traten über die vielen regionalen oder lokalen Wallfahrtszentren und bedeutsamen Wegstationen hinaus $^{50}$. Pilger und Pilgerstraßen machten diese Trias zu den zentralen Begegnungsund Erinnerungsorten der mittelalterlichen Christenheit. Von einem sonst unbekannten Jonas kündete sein dänischer Grabstein, er sei zweimal nach Jerusalem, dreimal nach Rom und einmal nach Santiago gepilgert ${ }^{51}$. Ähnliche Frömmigkeitsleistungen wenigstens einmal Jerusalem und Santiago, Rom vielleicht öfter - erbrachten im 12. Jahrhundert Herzog Heinrich der Löwe und viele seiner fürstlichen Standesgenossen ${ }^{52}$.

Am Petrusgrab orientierten sich Anspruch und Wirklichkeit des römischen Papsttums. Sein Geltungsanspruch blieb auch in erzwungener Reduktion stets universal, erfaßte aber faktisch nur jenes Abendland, für das der Ordnungsbegriff „Papsteuropa“ vorgeschlagen wurde ${ }^{53}$. Das Papsttum als Institution wie die römische sedes bildeten vor allem im Hoch- und Spätmittelalter den entscheidenden Bezugspunkt kirchlicher Existenz. Die internationale Forschung deckt derzeit beharrlich das in der Kurie zusammenlaufende Koordinatensystem der Papstkirche wie die daran anknüpfenden vielschichtigen Kommunikationsnetze auf ${ }^{54}$. Bei aller Nähe und Ferne zu den Nachfolgern Petri blieb im ganzen Mittelalter der Rang jener „lieux de mémoire“ unstrittig, die sich mit den Päpsten und ihrem Hof verbanden, ob in Rom, in Viterbo oder in Avignon materialisiert, ob zeitweise durch die großen Konzilien in Konstanz oder Basel substituiert ${ }^{55}$. Der Erinnerungsort Rom konnte wandern: Der institutionelle Abstraktionsprozeß war so weit vorangeschritten, daß Henricus de Segusio den berühmten Rechtssatz formulierte: ubi papa, ibi Roma - wo der Papst ist, da ist Rom.

\section{5) Die Vielfalt europäischer Erinnerungsorte im Mittelalter}


Viele „lieux de mémoire“ wurden in diesem knappen Abriß, der eher Perspektiven aufzeigen als das Thema abschließen wollte, nicht behandelt. Genannt werden soll wenigstens:

- Das Wissen um die monarchische Organisationsform politischer Verbände und die christliche Sendung der abendländischen Monarchien. Völker ohne Könige, wie die Alemannen oder Sachsen, gingen unter. Selbst im sozialen und institutionellen Wandel des Spätmittelalters wurde die monarchische oder wenigstens hierarchische Ordnung nicht prinzipiell in Frage gestellt ${ }^{56}$.

- Die Lehre von der abendländischen Funktionsverteilung von Priestertum, Königtum und Gelehrsamkeit (sacerdotium, regnum, studium), konkretisiert in der Zuordnung des Priestertums zu Italien, des Königtums zu Deutschland, des Studiums zu Frankreich $^{57}$.

- Die Vorstellung von der gesellschaftlichen Gliederung in drei Geburtsstände, die von geistlichen Autoren des frühen 11. Jahrhunderts als Grundlage aller Ordnung seit Anbeginn des Menschengeschlechts stilisiert wurde ${ }^{58}$.

- Das Netz vornehmer europäischer Bildungsstätten, im 10. und 11. Jahrhundert der Domschulen von Lüttich, Magdeburg, Reims oder Bamberg, im 12. und 13. Jahrhundert der entstehenden Universitäten in Bologna, Padua, Paris oder Oxford, Zielpunkte von Scholarenwanderungen und Erinnerungsorte einer europäisch agierenden Bildungsgesellschaft ${ }^{59}$.

- Endlich die Hierarchie unterschiedlicher Erinnerungsorte wie Aachen, St-Denis, Prag, Krakau oder Westminster mit Geltung für die entstehenden europäischen Nationen des Mittelalters, wie Nancy, Dijon, Florenz, Braunschweig, Wien oder StGilles mit integrierender Bedeutung für die werdenden Territorien und Fürstentümer $^{60}$. Ihre Vielfalt wie ihr Rang belegen die Tauglichkeit des auf Multizentralität zielenden Forschungsmodells „lieux de mémoire“ und seine Bedeutung für die europäische Geschichte, die für die mittelalterliche Geschichte Europas vor allem die seiner Teile meint.

Wir haben in diesem Beitrag Erinnerungsorte des Mittelalters von unterschiedlicher Qualität in den Blick genommen. Am Anfang stand das Wissen um die Einfügung Europas als dritter Teil der Welt in den Erdkreis. In der heilsgeschichtlichen Deutung wie im historischen Selbstbewußtsein wurde Europa zum Zielraum des größtmöglichen Fortschritts. Von den drei wichtigsten Erinnerungsorten Jerusalem, Rom und Santiago de Compostela ausgehend fragten wir nach Städten, Menschen und Institutionen mit ihren Vorstellungen und Ansprüchen. Als wichtiges Ergebnis konnten die strukturelle Offenheit wie flexible Anpassungsfähigkeit der hier betrachteten „lieux de mémoire“ 
benannt werden. Schließlich faßten wir das typisch mittelalterliche Wissen von der Dynamik und Veränderlichkeit der eigenen Welt. Sie entstand in gewaltigen Wanderungen der Völker, blieb erfüllt von der Kenntnis des Ausgangs wie des Zielpunkts des göttlichen Heils in Palästina, ließ sich niemals auf ein (wie auch immer geartetes) Kerneuropa eingrenzen und wurde getragen von Institutionen mit einem nicht auf Europa beschränkten, sondern über Europa hinausweisenden Geltungsanspruch.

Vom Ursprung wie von der Idee her ließen sich solche Erinnerungsorte kaum auf Europa reduzieren. Freilich formten sie die europäische Gedächtniskultur des Mittelalters, die sich aus ihrem Wissen um fremde Ursprünge und fremde Ziele nie in separierender Enge einrichten konnte. Erste Ideen von der Festung Europa blieben dem Ausgang des Mittelalters vorbehalten, als unter dem Eindruck der türkischen Bedrohung der Kontinent als Ideen-, Geschichts- und Wertegemeinschaft publizistisch entdeckt und propagiert wurde ${ }^{61}$. Just bei seinem faktischen Ausgriff auf die Welt richtete er sich in sendungsgeschichtlicher Selbstzufriedenheit ein, als er das universale Christentum faktisch für sich reklamierte und sein Konzept von Nation, Religion und Kultur über die Erdteile exportierte. Dabei ging das Wissen um die weiten multikulturellen Ursprünge Europas verloren. Erst die Migration der Moderne holt das neuzeitlich konstruierte Bollwerk des Glaubens, des Fortschritts und der Werte wieder ein. Heute würde man kaum noch die alte Verwandtschaft der trojanischen Brudervölker von Franken und Türken beschwören, die mit ihren frühmittelalterlichen Vorläufern ohnehin kaum noch etwas gemein haben. Das gezielte oder unbewußte Vergessen der weiten Wurzeln für das Werden Europas aus asiatischem Aufbruch erfährt derzeit auf ganz neue Weise sein hartes ökonomisch-demographisches „Update“. Aus längst vergangenen Zeiten könnte der Mediaevist einer Forschung über europäische Erinnerungsorte berichten, daß die Alten schon längst um die universalen Zusammenhänge, um die Selbstverständlichkeiten der verändernden Kraft von Migration und um die multikulturelle Prägung des in erster Linie nehmenden Europas wußten. Wer solche weiten Wurzeln kannte, durfte den Prozeß der christlichen Heilsgeschichte von Ost nach West mit einer gewissen Selbstsicherheit beschreiben. Borniertheiten aus einer ängstlichen Festungsmentalität, die weder ernsthaft zu empfangen noch zu geben vermochte, hätten die Konkurrenzfähigkeit der mittelalterlichen Kultur Europas dagegen rasch beendet. Die führenden Köpfe jenes Jahrtausends zwischen 500 und 1500, die ihr Europa ins universale Ensemble einfügten, wußten das noch. 
Mit Anmerkungen versehener Text eines Vortrags vom 21.3.2000 in der Villa Vigoni (Loveno di Menaggio/Italien), der für eine epochenübergreifende Diskussion griffige Thesen zuspitzen, mediaevistische Positionen abstecken, Perspektiven aufzeichnen und keine monographische Breite vorwegnehmen wollte.

Les lieux de mémoire, hrsg. von Pierre Nora, 3 Bde. in 6 Teilen, Paris 1984-1992.- Vgl. jetzt auch: Deutsche Erinnerungsorte, 3 Bde., hrsg. von Etienne François/Hagen Schulze, München 2001. Im Gegensatz zum französischen Vorbild bindet der deutsche Versuch vormoderne Erinnerungsorte furchtbar knapp ein. Das liefert damit einen weiteren Beleg dafür, daß die deutsche Erinnerung für ihre Gegenwart im europäischen Vergleich ungewöhnlich dicht, für ausgreifendere Epochen ungewöhnlich bescheiden verbleibt. Welche Auswirkungen dieses - aus aktuellen Herausforderungen durchaus einsichtige - Ungleichgewicht für die Stabilität politischer Kultur besitzt, wird sich erst aus künftigen Entwicklungen belegen lassen. Schon jetzt erscheinen Zweifel daran angebracht, wenige Jahrzehnte des vergangenen 20. Jahrhunderts zum Referenzmaßstab für die ganze nationale Erinnerung zu erheben. Diese Einschränkung will über das Grauen deutschen Handelns in der ersten Hälfte des 20. Jahrhunderts keinesfalls hinweggehen. Die Wirkkraft einer längeren Geschichte erfordert gleichwohl ihre eigene Berücksichtigung. In der Auflösung nationaler Strukturen unserer Gegenwart müssen die Deutschen - anders als andere europäische Völker - ihre Erinnerungen des 19. und 20. Jahrhunderts vielleicht nochmals leisten?

3 Memoria in der Gesellschaft des Mittelalters, hrsg. von Dieter Geuenich und Otto Gerhard Oexle, Göttingen 1994; Memoria als Kultur, hrsg. von Otto Gerhard Oexle, Göttingen 1995; Jan Assmann, Das kulturelle Gedächtnis. Schrift, Erinnerung und politische Identität in frühen Hochkulturen, München 1992.

Alain ERLANDE-BRANDENBURG, Le roi est mort. Études sur les funérailles, les sépultures et les tombeaux des rois de France jusqu'à la fin du XIII ${ }^{\mathrm{e}}$ siècle, Genève 1975; Joachim EHLERS, Kontinuität und Tradition als Grundlage mittelalterlicher Nationsbildung in Frankreich, in: Beiträge zur Bildung der französischen Nation im Früh- und Hochmittelalter, hrsg. von Helmut Beumann, Sigmaringen 1983, S. 15-47; Anne LOMBARD-JourdAN, „Montjoie et saint Denis!“ Le centre de la Gaule aux origines de Paris et de Saint-Denis, Paris 1989. Percy Ernst Schramm, Der König von Frankreich. Das Wesen der Monarchie vom 9. zum 16. Jahrhundert, 2 Bde., Darmstadt ${ }^{2} 1960$; La royauté sacrée dans le monde chrétien, hrsg. von Alain Boureau und Claudio Sergio Ingerflom, Paris 1992. Colette BEAUNE, Naissance de la nation France, Paris 1985; Jacques LE GofF, Ludwig der Heilige. Aus dem Französischen von Grete Osterwald, Stuttgart 2000. Marc BLOCH, Die wundertätigen Könige. Aus dem Französischen übersetzt von Claudia Märtl, München 1998; kritisch dazu Joachim EHLERS, Der wundertätige König in der monarchischen Theorie des Früh- und Hochmittelalters, in: Reich, Regionen und Europa in Mittelalter und Neuzeit. Festschrift für Peter Moraw, hrsg. von Paul-Joachim Heinig u. a., Berlin 2000, S. 3-19. Bernd SCHNEIDMÜLLER, Nomen patriae. Die Entstehung Frankreichs in der politischgeographischen Terminologie (10.-13. Jahrhundert), Sigmaringen 1987, S. 104 ff.; Thomas G. WALDMAN, Saint-Denis et les premiers Capétiens, in: Religion et culture autour de l'an Mil. Royaume capétien et Lotharingie, hrsg. von Dominique Iogna-Prat und Jean-Charles Picard, Paris 1990, S. 191-197; Joachim EHLERS, Politik und Heiligenverehrung in Frankreich, in: Politik und Heiligenverehrung im Hochmittelalter, hrsg. von Jürgen Petersohn, Sigmaringen 1994, S. 149175; Saint-Denis et la royauté. Études offertes à Bernard Guenée, hrsg. von Françoise Autrand u. a., Paris 1999.

5 Joachim EHLERS, Mittelalterliche Voraussetzungen für nationale Identität in der Neuzeit, in: Joachim Ehlers, Ausgewählte Aufsätze, Berlin 1996, S. 414-432; Benedykt ZIENTARA, Frühzeit der europäischen Nationen. Die Entstehung von Nationalbewußtsein im nachkarolingischen Europa. Aus dem Polnischen von Jürgen Heyde, Osnabrück 1997.

$6 \quad$ Robert Folz, Les saints rois du moyen âge en occident (VI'-XIII ${ }^{e}$ siècles), Bruxelles 1984; Politik und Heiligenverehrung im Hochmittelalter, hrsg. von Jürgen Petersohn, Sigmaringen 1994; André VAUCHEZ, La sainteté en occident aux derniers siècles du moyen âge d'après les procès de canonisation et les documents hagiographiques, Rome 1988; Wilfried EHBRECHT, Die Stadt und ihre Heiligen. Aspekte und Probleme nach Beispielen west- und norddeutscher Städte, in: Vestigia Monasteriensia. Studien zur Regionalgeschichte 5, 1995, S. 197-261 
Maria KLIPPEL, Die Darstellung der Fränkischen Trojanersage in Geschichtsschreibung und Dichtung vom Mittelalter bis zur Renaissance in Frankreich, Phil. Diss. Marburg 1936; Gert MELVILLE, Troja: Die integrative Wiege europäischer Mächte im ausgehenden Mittelalter, in: Europa 1500. Integrationsprozesse im Widerstreit, hrsg. von Ferdinand Seibt und Winfried Eberhardt, Stuttgart 1987, S. 415-432.

Peter MoRAw, Über Entwicklungsunterschiede und Entwicklungsausgleich im deutschen und europäischen Mittelalter. Ein Versuch, in: Peter Moraw, Über König und Reich. Aufsätze zur deutschen Verfassungsgeschichte des späten Mittelalters, hrsg. von Rainer Christoph Schwinges, Sigmaringen 1995, S. 293-320. Künftig: Deutschland und der Westen Europas, hrsg. von Joachim Ehlers (in Vorbereitung für 2002/03).

$9 \quad$ Werner Paravicini, Die ritterlich-höfische Kultur des Mittelalters, München 1994.

Dazu jetzt mit der älteren Literatur Heinz Thomas, Sprache und Nation. Zur Geschichte des Wortes deutsch vom Ende des 11. bis zur Mitte des 15. Jahrhunderts, in: Nation und Sprache. Die Diskussion ihres Verhältnisses in Geschichte und Gegenwart, hrsg. von Andreas Gardt, Berlin/New York 2000, S. 47-101.

Vgl. Ansätze und Diskontinuität deutscher Nationsbildung im Mittelalter, hrsg. von Joachim Ehlers, Sigmaringen 1989; Joachim EHLERS, Die Entstehung des deutschen Reiches, München 1994; Bernd SCHNEIDMÜLLER, Reich - Volk - Nation: Die Entstehung des deutschen Reiches und der deutschen Nation im Mittelalter, in: Mittelalterliche nationes - neuzeitliche Nationen. Probleme der Nationenbildung in Europa, hrsg. von Almut Bues und Rex Rexheuser, Wiesbaden 1995, S. 73-101.

12 Über Reisewege und Raumerfassung Carlrichard BRÜHL, Fodrum, Gistum, Servitium Regis. Studien zu den wirtschaftlichen Grundlagen des Königtums im Frankenreich und in den fränkischen Nachfolgestaaten Deutschland, Frankreich und Italien vom 6. bis zur Mitte des 14 . Jahrhunderts, 2 Bde., Köln/Graz 1968. Über die multizentrale Kulttradition Jürgen PETERSOHN, Kaisertum und Kultakt in der Stauferzeit, in: Politik und Heiligenverehrung (Anm. 6), S. 101-146.

František GRAUS, Lebendige Vergangenheit. Überlieferung im Mittelalter und in den Vorstellungen vom Mittelalter, Köln/Wien 1975.

Zu einer vergleichenden Geschichte Europas vgl. jetzt Michael BoRGOLTE, Vor dem Ende der Nationalgeschichten? Chancen und Hindernisse für eine Geschichte Europas im Mittelalter, in: Historische Zeitschrift 272 (2001), S. 561-596.

15 Bernd SCHNEIDMÜLLER, Die mittelalterlichen Konstruktionen Europas. Konvergenz und Differenzierung, in: „Europäische Geschichte“ als historiographisches Problem, hrsg. von Heinz Duchhardt und Andreas Kunz, Mainz 1997, S. 5-24.

Manfred Fuhrmann, Europa - Zur Geschichte einer kulturellen und politischen Idee, Konstanz 1981; Rudolf HiEsTAND, Europa im Mittelalter - vom geographischen Begriff zur politischen Idee, in: Europa - Begriff und Idee. Historische Streiflichter, hrsg. von Hans Hecker, Bonn 1991, S. 33-48; Peter SEGL, Europas Grundlegung im Mittelalter, in: Europa - aber was ist es? Aspekte seiner Identität in interdisziplinärer Sicht, hrsg. von Jörg A. Schlumberger und Peter Segl, Köln/Weimar/Wien 1994, S. 21-43.

Continuatio Hispana von 754 zu Isidors Historia, Monumenta Germaniae Historica. Auctores Antiquissimi, Bd. 11, hrsg. von Theodor Mommsen, Berlin 1894, S. 362.

Ottonische Neuanfänge. Symposion zur Ausstellung „Otto der Große, Magdeburg und Europa“, hrsg. von Bernd Schneidmüller und Stefan Weinfurter, Mainz 2001.

Vgl. Renate BaumgäRtel-Fleischmann, Der Sternenmantel Kaiser Heinrichs II. und seine Inschriften, in: Epigraphik 1988. Fachtagung für mittelalterliche und neuzeitliche Epigraphik, Graz, 10.-14. Mai 1988. Referate und Round-Table-Gespräche, hrsg. von Walter Koch, Wien 1990, S. 105-125. 
Michael BORGOLTE, „Europa ein christliches Land“. Religion als Weltstifterin im Mittelalter?, in: Zeitschrift für Geschichtswissenschaft 48 (2000), S. 1061-1077.

Zu den antiken Wurzeln Justus CoBET, Europa und Asien - Griechen und Barbaren - Osten und Westen. Zur Begründung Europas aus der Antike, in: Geschichte in Wissenschaft und Unterricht 47 (1996), S. 405-419.

Anna-Dorothee von den BRINCKEN, Europa in der Kartographie des Mittelalters, in: Archiv für Kulturgeschichte 55 (1973), S. 289-304; DiES., Kartographische Quellen: Welt-, See- und Regionalkarten, Turnhout 1988; DiEs., Fines terrae. Die Enden der Erde und der vierte Kontinent auf mittelalterlichen Weltkarten, Hannover 1992.

Honorius Augustodunensis, Imago mundi, hrsg. von Valerie I. J. Flint, in: Archives d'histoire doctrinale et littéraire du moyen âge 27 (1982), S. 7-151, hier S. 59-63.

Isidor von Sevilla, Etymologiae, hrsg. von W. M. Lindsay, Bd. 1, Oxford 1911, IX 2.

Jürgen FISCHER, Oriens - Occidens - Europa. Begriff und Gedanke „Europa“ in der späten Antike und im frühen Mittelalter, Wiesbaden 1957. Weiterführungen zum Hoch- und Spätmittelalter bietet jetzt Klaus OschemA, Der Europa-Begriff im Hoch- und Spätmittelalter. Zwischen geographischem Weltbild und kultureller Konnotation, in: Jahrbuch für Europäische Geschichte 2, 2001, S. 191-235. Herrn Oschema (Bamberg/Dresden) bin ich für wichtige Hinweise sehr verbunden.

Honorius Augustodunensis, Imago mundi (Anm. 24), S. 125.

Isidor von Sevilla, Etymologiae (Anm. 25), IX 2, 26-37; Gottfried von Viterbo, Speculum regum, hrsg. von Georg Waitz, in: Monumenta Germaniae Historica. Scriptores, Bd. 22, Hannover 1872, S. 21-93, hier S. 32.

Artikel „Jerusalem“, in: Theologische Realenzyklopädie, Bd. 16, Berlin/New York 1987, S. 590635; Otto BÖCHER, Artikel „Himmlisches Jerusalem“, in: Lexikon für Theologie und Kirche, Bd. 5, Freiburg/Brsg. u. a. ${ }^{3} 1996$, Sp. 129 f.

Ekkehart RoTTER, Abendland und Sarazenen. Das okzidentale Araberbild und seine Entstehung im Frühmittelalter, Berlin/New York 1986.

Carl ERDMANN, Die Entstehung des Kreuzzugsgedankens, Stuttgart 1935; Hans Eberhard MAYER, Geschichte der Kreuzzüge, Stuttgart/Berlin/Köln ${ }^{9} 2000$; Jonathan RILEY-Smith, The First Crusaders, 1095-1131, Cambridge 1997.

Guy LobRichon, Die Eroberung Jerusalems im Jahre 1099. Aus dem Französischen von Birgit Martens-Schöne, Sigmaringen 1998.

Klaus van EICKels und Tania BRÜsCH, Kaiser Friedrich II. Leben und Persönlichkeit in Quellen des Mittelalters, Düsseldorf 2000, S. 164 ff.; Wolfgang STÜRNER, Friedrich II. Teil 2: Der Kaiser 1220-1250, Darmstadt 2000, S. 157 ff.

Adso von Montier-en-Der, De ortu et tempore Antichristi necnon et tractatus qui ab eo dependunt, hrsg. von D. Verhelst, Turnhout 1976, S. 20-30.

Hannes MöHrING, Der Weltkaiser der Endzeit. Entstehung, Wandel und Wirkung einer tausendjährigen Weissagung, Stuttgart 2000.

Karl HAUCK, Von einer spätantiken Randkultur zum karolingischen Europa, in: Frühmittelalterliche Studien 1 (1967), S. 3-93.

Fredegar, Cronicae, hrsg. von Bruno Krusch, in: Monumenta Germaniae Historica. Scriptores rerum Merovingicarum, Bd. 2, Hannover 1888, III 2, S. 93. Übersetzung aus: Quellen zur Geschichte des 7. und 8. Jahrhunderts, Darmstadt 1982, S. 85.

KLIPPEL, Darstellung (Anm. 7); GrAus, Lebendige Vergangenheit (Anm. 13), S. 81 ff.

Eine Zusammenstellung des Herkunftswissens der deutschen Völker und der Deutschen von Julius Caesar nahmen erstmals das Annolied im 11. und die mittelhochdeutsche Kaiserchronik im 12. Jahrhundert vor: Das Annolied, hrsg. von Eberhard Nellmann, Stuttgart ${ }^{4} 1996$, S. 24-34; Die Kaiserchronik eines Regensburger Geistlichen, hrsg. von Edward Schröder, Hannover 1892, S. 84- 
86. Vgl. Heinz ThomAs, Julius Caesar und die Deutschen. Zu Ursprung und Gehalt eines deutschen Geschichtsbewußtseins in der Zeit Gregors VII. und Heinrichs IV., in: Die Salier und das Reich, Bd. 3, hrsg. von Stefan Weinfurter, Sigmaringen 1991, S. 245-277.

Jordanes, Romana et Getica, hrsg. von Theodor Mommsen, Berlin 1882, S. 56, 60. Vgl. Margit PFEIFER, Skandinavien - Officina gentium ... vagina nationum (Jordanis Getica, IV, 25). Die Herkunft der Germanenstämme aus Skandinavien in den Geschichtswerken des Mittelalters und der Humanisten, Phil. Diss. (masch.) Innsbruck 1967.

41 Reinhard Wenskus, Stammesbildung und Verfassung. Das Werden der frühmittelalterlichen gentes, Köln/Graz 1961; Herwig WolfRAM, Die Goten. Von den Anfängen bis zur Mitte des sechsten Jahrhunderts. Entwurf einer historischen Ethnogenese, München ${ }^{2} 1990$; Ethnogenese und Überlieferung. Angewandte Methoden der Frühmittelalterforschung, hrsg. von Karl Brunner und Brigitte Merta, Wien/München 1994; Historiographie im frühen Mittelalter, hrsg. von Anton Scharer und Georg Scheibelreiter, Wien/München 1994; Strategies of Distinction. The Construction of Ethnic Communities, 300-800, hrsg. von Walter Pohl mit Helmut Reimitz, Leiden/Boston/Köln 1998; Walter PoHL, Die Germanen, München 2000; Ernst PITZ, Die griechisch-römische Ökumene und die drei Kulturen des Mittelalters. Geschichte des mediterranen Weltteils zwischen Atlantik und Indischem Ozean 270-812 (Europa im Mittelalter 3), Berlin 2001.

Historia Welforum, hrsg. von Erich König, Sigmaringen ${ }^{21978, ~ S . ~ 2 / 4 . ~}$

Friedrich PRINZ, Von Konstantin zu Karl dem Großen. Entfaltung und Wandel Europas, Düsseldorf/Zürich 2000. Für die Folgezeit Robert BARTLETT, The Making of Europe. Conquest, Colonization and Cultural Change 950-1350, Princeton 1993.

Johannes FRIED, Römische Erinnerung. Zu den Anfängen und frühen Wirkungen des christlichen Rommythos, in: Studien zur Geschichte des Mittelalters. Jürgen Petersohn zum 65. Geburtstag, hrsg. von Matthias Thumser u. a., Stuttgart 2000, S. 1-41.

Arturo GRAF, Roma nella memoria e nelle immaginazioni del medio evo, Torino 1923; Eugenio DUPRÉ THESEIDER, L'idea imperiale di Roma nella tradizione del medioevo, Milano 1942; Robert Folz, L'idée d'Empire en occident du Ve au XIV ${ }^{e}$ siècle, Paris 1953; Gerd TellennBACH, Die Stadt Rom in der Sicht ausländischer Zeitgenossen (800-1200), in: Saeculum 24 (1973), S. 1-40; Michele Maccarrone, Romana ecclesia cathedra Petri, hrsg. von Piero Zerbi u. a., 2 Bde., Roma 1991.

Jürgen Petersohn, Artikel „Romidee“, in: Lexikon des Mittelalters, Bd. 7, München 1995, Sp. 1007-1009.

Percy Ernst Schramm, Kaiser, Rom und Renovatio. Studien zur Geschichte des römischen Erneuerungsgedankens vom Ende des karolingischen Reiches bis zum Investiturstreit, Leipzig 1929, S. 87 ff. Neuere Deutungen (mit wichtigen Modifikationen und Korrekturen) bei Knut GÖRICH, Otto III. Romanus Saxonicus et Italicus. Kaiserliche Rompolitik und sächsische Historiographie, Sigmaringen 1993; Gerd AlthOFF, Otto III., Darmstadt 1996; Herwig WolfRAM, Konrad II. 990-1039. Kaiser dreier Reiche, München 2000.

Beispiel: Die Lieder des Archipoeta. Lateinisch und deutsch, hrsg. von Karl Langosch, Stuttgart 1973, S. 36. Vgl. Hans Joachim KIRFEL, Weltherrschaftsidee und Bündnispolitik. Untersuchungen zur auswärtigen Politik der Staufer, Bonn 1959. Korrekturen bei Karl Ferdinand WERNER, Das hochmittelalterliche Imperium im politischen Bewußtsein Frankreichs (10.-12. Jahrhundert), in: Historische Zeitschrift 200 (1965), S. 1-60.

Klaus HERBERS, Der Jakobusweg, Tübingen ${ }^{6} 1998$.

Unterwegssein im Spätmittelalter, hrsg. von Peter Moraw, Berlin 1985; Raymond OuRSEL, Pèlerins du Moyen Age. Les hommes, les chemins, les sanctuaires, Paris ${ }^{2} 1978$; Jean RICHARD, Les récits de voyages et de pèlerinages, Turnhout 1981.

51 Edmond-René LABANDE, Recherches sur les pèlerins dans l'Europe du XI ${ }^{e}$ et XII ${ }^{e}$ siècles, in: Cahiers de civilisation médiévale 1 (1958), S. 159-169, hier S. 167; korrigierte Datierung von V. Almazán bei HerBers, Jakobusweg (Anm. 49), S. 19. Vgl. auch Ursula GANZ-BLÄTtLER, Andacht und Abenteuer. Berichte europäischer Jerusalem- und Santiago-Pilger (1320-1520), Tübingen 1990. 
Reinhold RÖHRICHT, Die Deutschen im Heiligen Lande, Innsbruck 1894.

Hans-Joachim SCHMIDT, Kirche, Staat, Nation. Raumgliederung der Kirche im mittelalterlichen Europa, Weimar 1999.

Vgl. Brigide ScHWARZ, Klerikerkarrieren und Pfründenmarkt. Perspektiven einer sozialgeschichtlichen Auswertung des Repertorium Germanicum, in: Quellen und Forschungen aus italienischen Archiven und Bibliotheken 71 (1991), S. 243-265; DIES., Römische Kurie und Pfründenmarkt im Spätmittelalter, in: Zeitschrift für historische Forschung 20 (1993), S. 129-152. Im Druck zu erwarten ist die Kölner Habilitationsschrift von Götz-Rüdiger TEWES, Rom und Europa vor der Reformation (masch. 1997).

Erich Meuthen, Das 15. Jahrhundert, München/Wien 1980; Walter BrandMÜLleR, Das Konzil von Konstanz 1414-1418, 2 Bde., Paderborn u. a. 1991-1997; Johannes HelmRATH, Das Basler Konzil 1431-1449. Forschungsstand und Probleme, Köln/Wien 1987; Heribert MüLLER, Die Franzosen, Frankreich und das Basler Konzil (1431-1449), 2 Bde., Paderborn u. a. 1990.

56

Matthias BECHER, Non enim habent regem idem Antiqui Saxones. Verfassung und Ethnogenese in Sachsen während des 8. Jahrhunderts, in: Studien zur Sachsenforschung, hrsg. von Hans-Jürgen Häßler, Oldenburg 1999, S. 1-31; Das spätmittelalterliche Königtum im europäischen Vergleich, hrsg. von Reinhard Schneider, Sigmaringen 1987; Bernhard TÖPFER, Urzustand und Sündenfall in der mittelalterlichen Gesellschafts- und Staatstheorie, Stuttgart 1999.

(1)

Alexander von Roes, Noticia seculi, hrsg. von Herbert Grundmann und Hermann Heimpel, Stuttgart 1958, cap. 12, S. 159. Dazu Manfred FuhrmanN, Alexander von Roes: ein Wegbereiter des Europagedankens?, in: Sitzungsberichte der Heidelberger Akademie der Wissenschaften. Philosophisch-historische Klasse 1994, 4, Heidelberg 1994; ScHMIDT, Kirche (Anm. 53), S. 525. Vgl. auch Werner GoEz, Translatio Imperii. Ein Beitrag zur Geschichte des Geschichtsdenkens und der politischen Theorien im Mittelalter und in der frühen Neuzeit, Tübingen 1958.

Georges Duby, Die drei Ordnungen. Das Weltbild des Feudalismus, Frankfurt/Main 1981; Otto Gerhard OEXLE, Deutungsschemata der sozialen Wirklichkeit im frühen und hohen Mittelalter. Ein Beitrag zur Geschichte des Wissens, in: Mentalitäten im Mittelalter, hrsg. von František Graus, Sigmaringen 1987, S. 65-117.

C. Stephen JAEGER, The Envy of Angels. Cathedral Schools and Social Ideals in Medieval Europe, 950-1200, Philadelphia 1994; Joachim EHLERS, Dom- und Klosterschulen in Deutschland und Frankreich im 10. und 11. Jahrhundert, in: Schule und Schüler im Mittelalter. Beiträge zur europäischen Bildungsgeschichte des 9. bis 15. Jahrhunderts, hrsg. von Martin Kintzinger u. a., Köln/Weimar/Wien 1996, S. 29-52; Joachim EHLERS, Die hohen Schulen, in: Ders., Ausgewählte Aufsätze, Berlin 1996, S. 115-142. Peter ClASSEN, Studium und Gesellschaft im Mittelalter, hrsg. von Johannes Fried, Stuttgart 1983; Schulen und Studium im sozialen Wandel des hohen und späten Mittelalters, hrsg. von Johannes Fried, Sigmaringen 1986; A History of the University in Europe, Bd. 1: Universities in the Middle Ages, hrsg. von Hilde de Ridder-Symoens, Cambridge 1992; Jacques Verger, Les gens de savoir dans l`Europe à la fin du Moyen Age, Paris 1997.

Vgl. die Bände der Reihe „Residenzenforschung“. Überblick für das Reich: Materialien zum Werk: Fürstliche Höfe und Residenzen im spätmittelalterlichen Reich. Ein dynastischtopographisches Handbuch, bearb. von Jan Hirschbiegel und Jörg Wettlaufer, Kiel 1999.

Die Idee Europa 1300-1946. Quellen zur Geschichte der politischen Einigung, hrsg. von Rolf Hellmut Foerster, München 1963; HiESTAND, Europa (Anm. 16); Segl, Europas Grundlegung (Anm. 16). 